\title{
ESTUDO CLÍNICO PROSPECTIVO EM HUMANOS - COMPARANDO O PAPEL DA LESÃO DE ISQUEMIA-REPERFUSÃO EM ENXERTOS ESTEATÓTICOS VS NÃO ESTEATÓTICOS NO TRANSPLANTE HEPÁTICO
}

\author{
Prospective study comparing steatotics vs non steatotics grafts in liver transplant - The role of ischemia \\ I reperfusion injury
}

\author{
Huda Maria Noujaim¹, Edna Frasson de Souza Montero², Cristiane Ribeiro³, Vera Cappelozzi4, Regina Santos', Fábio Crescentini', \\ Marcelo Perosa de Miranda', Tércio Genzini ${ }^{1}$
}

\begin{abstract}
RESUMO
Introdução: Vários fatores estão associados à lesão de isquemia fria e reperfusão quente no transplante hepático, tais como infiltrado de neutrófilos e linfo-plasmocitário, liberação de citoquinas inflamatórias e apoptose. Porém, pouco se conhece sobre o papel da isquemia/ reperfusão em enxertos esteatóticos. Objetivo: avaliar o papel da lesão de isquemia/reperfusão no transplante hepático em humanos comparando enxertos esteatóticos e não esteatóticos. Pacientes e métodos: Entre maio/02 e março/07 foram realizadas 84 biópsias pós-reperfusão (2hs após reperfusão) e 18 pré-reperfusões, totalizando 84 transplantes hepáticos em 82 pacientes. As biópsias foram agrupadas em cinco grupos, de acordo com o grau de macro e microesteatose: GEL-leve (<30\%), GEM- moderada (30-59\%), GEGgrave ( $\geq 60 \%)$, GEA- sem esteatose, GPR-pré-reperfusão. Nas 102 biópsias foram analisadas: porcentagens de macro e microesteatose, graus de exsudato de neutrófilos (0-3) e infiltrado linfo-plasmocitário portal (0-3), índices de apoptose (métodos de Túnel e caspase-3) e ICAM-1. As esteatoses macro (n-49) e microvesicular (n-74) foram individualmente analisadas e classificadas em graus leve (G1), moderado (G2), grave (G3) e ausente (G4). Resultados: $\mathrm{O}$ índice de apoptose (TUNEL) foi: $\mathrm{GEL}=0.262 \pm 0.111, \mathrm{GEM}=0.278 \pm 0.113$, GEG= $0.244 \pm 0.117$, GEA $=0,275 \pm 0.094$ e GPR $=0.181 \pm 0.123$, p- 0.07 . No grupo macroesteatose o índice de apoptose (TUNEL) foi: G1 $=0.284 \pm$ $0.106, \mathrm{G} 2+3=0.160 \pm 0.109, \mathrm{G} 4=0,275 \pm 0.094, \mathrm{p}-0.05$; e no grupo microesteatose, G1 $=0.222 \pm 0.123, \mathrm{G} 2+3=0.293 \pm 0.108, \mathrm{G} 4=0.275 \pm 0.094$, p-0.049. Não existiu diferença estatística entre grupos ao analisarmos os índices de apoptose (caspase-3) e ICAM-1. Conclusão: Os grupos de esteatose grave e macroesteatose (grau moderado e grave) apresentaram significante redução no índice de apoptose, enquanto o grupo microesteatose (moderado e grave) teve significante aumento.
\end{abstract}

Descritores: Isquemia, Reperfusão, Transplante, Fígado, Apoptose, ICAM-1

\footnotetext{
Instituições:

${ }^{1}$ Departamento de transplantes de órgãos da HEPATO - Hospital Beneficência Portuguesa de São Paulo

${ }^{2}$ Departamento de Técnica Operatória da EPM / UNIFESF

${ }^{3}$ Centro Integrado de Patologia do Hospital Beneficência Portuguesa de São Paulo

4 Laboratório de Imuno-histoquímica da FMUSP
}

\section{Correspondência:}

Huda Maria Noujaim

Rua Rodrigo Claudio 58, apto 8, CEP 01532-020, São Paulo /SP

Fones: (11) 33416212, (11) 85579800 - Fax: (11) 3266-8072

Email-hudanoujaim@hotmail.com

\section{INTRODUÇÃO}

$\mathrm{O}$ transplante hepático $(\mathrm{TxH})$ é a terapia de escolha para pacientes portadores de doenças hepáticas terminais e insuficiência hepática aguda. ${ }^{1-3}$

A cada ano, a necessidade de TxH tem aumentado de forma exponencial, enquanto a disponibilidade de enxertos atinge um platô. ${ }^{4}$

A fim de se expandir o pool de doadores falecidos, têm sido utilizados portadores de sorologias positivas para vírus da hepatite $\mathrm{B}$ (anti $\mathrm{HBc}+$ ) ou $\mathrm{C}$, Chagas, sífilis ou enxertos com esteatose.

A prevalência de obesidade e diabetes aumenta na população geral, sendo esses fatores fortemente relacionados ao desenvolvimento de esteatose. ${ }^{5-8}$ Estima-se que 20\% a 40\% dos fígados de doadores falecidos são esteatóticos ${ }^{9} \mathrm{e} 1 / 3$ deles são descartados. ${ }^{10} 23 \%$ a $35 \%$ dos doadores vivos apresentavam mais de $10 \%$ de esteatose. ${ }^{11,12}$

A presença de esteatose nos enxertos hepáticos está associada ao aumento do não-funcionamento primário do enxerto (PNF), à necessidade de re-transplante e diminuição na sobrevivência 
dos receptores no primeiro ano pós-transplante (67-69\% vs. $86-87 \%)^{4,13,14}$ Enquanto a microesteatose apresenta resultados similares aos dos enxertos sem esteatose, ${ }^{15,16}$ a esteatose macrovesicular aumenta a incidência de PNF em 5,1\%, comparado a 1,8\% dos enxertos sem esteatose, diminuindo a sobrevivência dos pacientes (77\% versus $91 \%$ ) daqueles sem esteatose e enxertos ( $70 \%$ versus $82 \%){ }^{17}$

Os enxertos hepáticos com 30 a $60 \%$ de esteatose são classificados como sub-ótimos, por aumentarem o risco de $\mathrm{PNF},{ }^{6,18,19}$ porém, são transplantados em pacientes sem fatores de riscos adicionais ou em situações críticas, no qual se justifica enfrentar tais riscos. ${ }^{20} \mathrm{Com} o$ aumento da demanda de enxertos para transplante, muitos centros têm utilizado fígados com esteatose moderada e grave. ${ }^{21}$

Os mecanismos pelos quais a presença de esteatose nos enxertos hepáticos para transplante causa PNF ou disfunção primária não são completamente entendidos. ${ }^{20,22}$ Alguns mecanismos têm sido propostos em fígados esteatóticos, tais como: 1.diminuição do fluxo sanguíneo portal - com a balonizacão dos hepáticos ocorre uma distorção da luz dos sinusóides, aumentando a resistência e diminuindo o fluxo sangüíneo e, conseqüentemente, causando isquemia secundária nos enxertos; ${ }^{23,24}$ 2. deficiência no metabolismo anaeróbico - os hepatócitos esteatóticos aumentam o não-acoplamento de proteínas e diminuem a produção de ATP mitocôndria; ${ }^{25-27}$ 3. efeitos físicos dos lipídeos - alterações na membrana plasmática dos sinusóides em fígados esteatóticos proporcionam aumento da ativação e adesão das células de Kupffer na reperfusão. Enquanto durante a isquemia fria os lipídeos podem solidificar causando ruptura dos hepatócitos ${ }^{28,29}$ e 4. aumento dos efeitos do estresse oxidativo na reperfusão - fígados esteatóticos são de base predispostos ao estresse oxidativo, sendo este o componente chave da lesão de reperfusão do novo enxerto..$^{30-32}$

Atualmente, medidas terapêuticas têm sido investigadas a fim de superar os desafios da esteatose no transplante hepático e, assim, expandir os critérios para utilização desses enxertos. ${ }^{22,33}$

A lesão de isquemia fria / reperfusão quente (IF/RQ) é responsável pelo não funcionamento de aproximadamente $10 \%$ dos enxertos hepáticos. ${ }^{34}$ Esse processo é desencadeado já durante a preservação fria do enxerto, na qual os tecidos encontram-se em anóxia e são observados distúrbios do metabolismo de energia intracelular e redução dos níveis celulares de adenosina tri-fosfato (ATP). ${ }^{35} \mathrm{Com}$ a reperfusão, o fluxo sangüíneo e a oxigenacão do enxerto são restabelecidos, porém agravam a lesão isquêmica existente devido à formação de espécies reativas de oxigênio. ${ }^{36}$

Como conseqüências da lesão de IF/RQ no parênquima hepático são observadas: infiltração de neutrófilos, ativação dos macrófagos/ células de kupffer e formação de citoquinas, ${ }^{37}$ resultando em lesão microvascular, hipoperfusão, extensa lesão celular e insuficiência do enxerto com conseqüências fatais aos pacientes. Tempo de isquemia fria acima de 12 horas, ${ }^{38}$ doadores maiores de 50 anos e presença de esteatose favorecem a lesão de IF/RQ. ${ }^{39}$

Os achados histológicos atribuídos à lesão de IF/RQ incluem a presença de esteatose microvesicular, infiltrados focais de neutrófilos no parênquima hepático, colestase, balonização dos hepatócitos, necrose e apoptose ${ }^{40}$ e são fatores preditores da função dos enxertos. ${ }^{41-43}$

Evidências sugerem ser a apoptose o mecanismo decisivo durante a fase inicial da lesão de IF/RQ hepática em animais ${ }^{44,45} \mathrm{e}$ humanos, ${ }^{46,47}$ mediada através da ativação das caspases. ${ }^{36,48-51}$ As caspases são as principais executoras da apoptose nos neutrófilos humanos. ${ }^{52,53}$ Outras proteases como a calpains e catepsina B estão envolvidas no processo de IF/RQ hepática. ${ }^{54,55}$

A lesão de IF/RQ hepática induzida pela apoptose resulta no desenvolvimento e exacerbação da disfunção primária e PNF dos enxertos, representando risco eminente de vida ao receptor. ${ }^{42,56,57} \mathrm{~A}$ insuficiência hepática é a manifestação dessa complicação, expressa através de insuficiência cardiovascular, síndrome hepatorrenal e encefalopatia grau IV. Nessas situações, o retransplante precoce é o único tratamento para evitar o desenvolvimento de edema cerebral irreversível ou insuficiência de múltiplos órgãos. ${ }^{56}$

\section{OBJETIVOS}

Os objetivos deste estudo são avaliar os marcadores e os fatores envolvidos na lesão de isquemia fria e reperfusão quente, comparando enxertos com e sem esteatose e o impacto da esteatose na sobrevivência de pacientes e enxertos pós TxH.

\section{PACIENTES E MÉTODOS}

Este é um estudo prospectivo, realizado no período de 01/maio de 2002 e 01/março de 2007 na Real e Benemérita Associação Portuguesa de Beneficência de São Paulo pela equipe de transplante de órgãos HEPATO, no qual foram avaliados pacientes submetidos a transplante hepático. O estudo foi aprovado pelo Comitê de Ética do Hospital Beneficência Portuguesa e a análise dos marcadores da lesão de isquemia e reperfusão pelo Comitê de Ética em Pesquisa da EPM/ UNIFESP (protocolo n¹100/07).

Os critérios de inclusão dos pacientes foram: portadores de doença hepática aguda (insuficiência hepática aguda) e crônica hemodinamicamente estáveis, re-transplante (somente para pacientes já incluídos no estudo) e os que receberam enxertos de doadores falecidos. Foram excluídos do estudo os pacientes que evoluíram a óbito nos primeiros sete dias de pós-operatório, os que receberam enxertos reduzidos (doadores vivos, fígados bipartidos ou reduzidos), os menores de 15 anos e os receptores hemodinamicamente instáveis (altas doses de drogas vasoativas) pré TxH.

Nossa amostra foi composta de 84 transplantes hepáticos realizados em 82 pacientes, sendo dois retransplantes.

Os $84 \mathrm{TxH}$ foram divididos em quatro grupos, de acordo com o grau de esteatose dos enxertos em: ausente, leve $(<30 \%)$, moderado (30 $-59 \%$ ) e grave $(\geq 60 \%)$, assim distribuídos: GEA -esteatose ausente (n-21), GEL -esteatose leve (n-29), GEM -esteatose moderada (n22), GEG - esteatose grave (n-12). Em 18 casos realizou-se biópsia pré-reperfusão (no tempo do back table) constituindo o GPR -grupo pré-reperfusão (n-18). Também analisamos isoladamente a esteatose macrovesicular e microvesicular e as classificamos em graus leve, moderado e grave.

Os parâmetros estudados nos 84 doadores cadáveres foram obtidos a partir da ficha da Secretaria do Estado da Saúde, Sistema Estadual de Transplantes, Informações sobre doador de múltiplos órgãos que incluem: idade, sexo, peso, altura, índice de massa corpórea, grupo sangüíneo, causas de óbito, dias em UTI, presença de parada cardiorrespiratória e de infecções, utilização de 
drogas vasoativas, sorologias (Chagas, HIV, HTLV I/ II, HbsAg, anti-HBs, anti-HBc, anti-HCV, CMV, toxoplasmose) e avaliação dos níveis séricos de AST, ALT, fosfatase alcalina, Gama GT, bilirubinas e sódio. A média e o desvio padrão da idade (anos), peso $(\mathrm{Kg})$ e índice de massa corpórea dos doadores foram: idade: $\mathrm{GEL}=42,69 \pm 16,65 ; \mathrm{GEM}=42,59 \pm 12,79 ; \mathrm{GEG}=39,67 \pm 16,20$; GEA $=42,90 \pm 12,27,(p=0,9)$; peso: $\mathrm{GEL}=71,93 \pm 10,07 ; \mathrm{GEM}=72,14 \pm 15$ $, 11 ; \mathrm{GEG}=7,00 \pm 16,06$; GEA $=72,05 \pm 9,72$ ( $\mathrm{p}=0,6)$; e índice de massa corpórea: $\mathrm{GEL}=25,52 \pm 3,24, \mathrm{GEM}=25,35 \pm 3,36 ; \mathrm{GEG}=23,78 \pm 4,23$; $\mathrm{GEA}=24,91 \pm 2,45(\mathrm{p}=0,4)$. A causa mais freqüente de óbito foi acidente vascular cerebral em GEL $=15(51,7 \%), \mathrm{GEM}=15(68,2 \%)$, $\mathrm{GEG}=6(50 \%), \mathrm{GEA}=15(71,4 \%),(\mathrm{p}=0,45)$.

Nos grupos GEL, GEM, GEG e GEA, respectivamente, a média dos dias em UTI foi de $5,2 \pm 4,4 ; 3,6 \pm 3,0 ; 4,7 \pm 3,5$ e $6,9 \pm 4,3(\mathrm{p}=0,06)$ e dos níveis séricos de $\mathrm{AST}=130,0 \pm 173 \mathrm{U} / \mathrm{L}$; $94,2 \pm 72,0 \mathrm{U} / \mathrm{L} ; 99,7 \pm 111,4 \mathrm{U} / \mathrm{L} ; 247,5 \pm 803,6 \mathrm{U} / \mathrm{L} ;(\mathrm{p}=0,6)$; $\underline{\text { ALT }}=90,9 \pm 113,4 \mathrm{U} / \mathrm{L} ; 64,9 \pm 49,6 \mathrm{U} / \mathrm{L} ; 79,8 \pm 61,4 \mathrm{U} / \mathrm{L} ; 154,1 \pm 230,4 \mathrm{U} / \mathrm{L}$ $(\mathrm{p}=0,2)$; bilirrubina total $=0,99 \pm 1,31 \mathrm{mg} / \mathrm{dL} ; 0,85 \pm 0,60 \mathrm{mg} / \mathrm{dL}$; $0,77 \pm 0,44 \mathrm{mg} / \mathrm{dL} ; 0,9 \pm 0,79 \mathrm{mg} / \mathrm{dL} ; \mathrm{p}=0,9$ e sódio $=154,3 \pm 17,9 \mathrm{mMol} / \mathrm{L}$; $154,7 \pm 11,2 \mathrm{mMol} / \mathrm{L} ; 154,6 \pm 16,1 \mathrm{mMol} / \mathrm{L} ; 154,9 \pm 16,8 \mathrm{mMol} / \mathrm{L}(\mathrm{p}=1,0)$. $\mathrm{O}$ número de enxertos repassados por outras equipes e por nós transplantados foi em GEL, GEM, GEG e GEA, respectivamente: $11(37,9 \%) ; 7(31,8 \%) ; 5(41,7 \%)$ e $3(14,3 \%) \quad(p=0,6)$.

Os parâmetros analisados dos 82 receptores em GEL ( $\mathrm{n}=29)$, GEM $(\mathrm{n}=20)$, GEG $(\mathrm{n}=12)$ e GEA ( $\mathrm{n}=21)$ foram, respectivamente, média de idade (anos) \pm desvio padrão $=51,6 \pm 10,6 ; 46,7 \pm 12,5 ; 54 \pm 7,8$; $52,3 \pm 10,6(\mathrm{p}=0,2)$ e peso $(\mathrm{Kg}) 70,7 \pm 11,7 ; 77,3 \pm 14,9 ; 69,2 \pm 9,1$; $75,9 \pm 13,8(\mathrm{p}=0,2)$. A maioria dos pacientes era do sexo (masculino) em GEL $=25(86,2 \%)$, GEM=18 (90\%), GEG=8 (66,7\%), GEA=19 $(90,5 \%)(\mathrm{p}=0,2)$.

Também foram avaliadas indicações de TxH, tempo de espera em lista pré-TxH e tempo de internação após o TxH. As condições clínicas dos receptores portadores de doença hepática crônica foram avaliadas através do escore MELD calculado no dia do transplante.

As soluções de preservação utilizadas em GEL, GEM, GEG, GEA foram respectivamente: $\mathrm{UW}$ exclusivo (5litros) $=8(27,6 \%), 6$ $(27,3 \%), 3(25 \%), 5(23,8 \%)$; UW (3litros) + EC (2litros) $=18(62,1 \%)$, $14(63,6 \%), 6(50 \%), 14(66,7 \%)$ e outras= $3(10,3 \%), 2(9,1 \%), 3$ $(25 \%), 2(9,5 \%)(\mathrm{p}=0,9)$.

A maioria dos transplantes foi realizada utilizando a técnica de Piggy back em GEL, GEM, GEG e GEA, respectivamente: 27 (93,1\%), $19(86,4 \%), 11(91,7 \%)$ e $18(85,7 \%), p=0,8$; no restante, utilizou-se técnica convencional.

Os esquemas de imunossupressão aplicados em GEL, GEM, GEG, GEA foram respectivamente: ciclosporina+ micofenolato mofetil + prednisona $=19(65,5 \%), 10(45,5 \%), 7(58,3 \%), 12(57,1 \%) ;$ FK $506+$ prednisona $=10(34,5 \%), 8(36,4 \%), 1(8,3 \%), 7(33,3 \%)$ e nos demais casos associou-se micofenolato ao FK 506 e prednisona, $(\mathrm{p}=0,6)$.

Também foram avaliados: tempo de isquemia fria, tempo de cirurgia, transfusão de concentrado de hemáceas e presença de rejeição celular aguda (confirmada através de biópsia hepática).

A função dos enxertos hepáticos foi avaliada nos sete dias iniciais de pós-operatório, através dos níveis séricos de AST, ALT, fosfatase alcalina, Gama GT, bilirubinas, tempo de protrombia e a função renal, através dos níveis de uréia e creatinina e comparado entre os grupos. As causas de perda do enxerto transplantado e de óbitos foram divididas em precoces (<30dias pós TxH) e tardias (30 dias pós-operatório).

As sobrevivências de pacientes e enxertos serão comparadas entre os quatro grupos de estudo excluindo o grupo referência.

As amostras teciduais do enxerto transplantado foram obtidas duas horas após a reperfusão arterial. Esse material foi resultante de biópsia hepática realizada no lobo esquerdo em cunha de $1,5 \mathrm{~cm}$ de profundidade, que foi imediatamente conservado em formol a $10 \%$ e enviado ao Centro Integrado de Patologia da Real e Benemérita Associação Portuguesa de Beneficência de São Paulo.

\section{Avaliação histológica das amostras de fígado}

As biópsias hepáticas foram fixadas em formol a $10 \%$ e submetidas a processamento de rotina para inclusão em parafina.

\section{Protocolo para preparo das lâminas de hematoxilina-eosina (HE)}

Cada bloco de parafina contendo a biópsia hepática foi cortado em micrótomo à espessura de 3 micra por corte e transferido para lâminas de vidro. Essas lâminas foram desparafinizadas em estufa a $75^{\circ} \mathrm{C}$, coradas pelo método de H.E por cinco minutos, a seguir lavadas e coradas em solução de Eosina por um minuto. Posteriormente, as laminas foram lavadas quatro vezes em álcool absoluto e mais quatro vezes em xilol, fixadas com lamínulas e prontas para serem analisadas.

\section{Protocolo para preparo das lâminas silanizadas}

As lâminas silanizadas (3-Aminopropil-trietoxi-silano- Sigma) foram preparadas de acordo com o seguinte protocolo: os blocos de parafina contendo as biópsias hepáticas foram armazenados em freezer a $-10^{\circ} \mathrm{C}$, posteriormente cortados em fatias de 3 micra, transferido ao banho histológico a $60^{\circ} \mathrm{C}$, colocados em lâminas silanizadas, que permaneceram por 24 horas em estufa a $70^{\circ} \mathrm{C}$ e após prontas para realização das provas de imuno-histoquimica.

\section{Protocolo Imuno-histoquímico para o Anticorpo ICAM-1(CD54)}

A imuno-histoquímica utilizada para a pesquisa do anticorpo em tecido foi realizada pelo método Peroxidase. Os cortes histológicos a $3 \mu \mathrm{m}$ de espessura foram realizados em lâminas silanizadas (3-Aminopropil-trietoxi-silano- Sigma) e seguiu-se o protocolo: as lâminas foram desparafinadas em xilol e hidratadas em álcool absoluto, 95\%, 70\% e água corrente; seguiu-se um bloqueio da peroxidade endógena com água oxigenada $\left(\mathrm{H}_{2} \mathrm{O}_{2}\right) 10 \mathrm{~V} 3 \%$ por sete vezes de cinco minutos, seguida de lavagem com água e PBS e, após, mais um bloqueio com kit DakoCytomation - Biotin Blocking System, cod.X0590, marca DakoCytomation. Depois de todos os bloqueios, as lâminas foram mergulhadas em ácido fórmico por três minutos, lavadas em água corrente e PBS. Seguiu-se a recuperação antigênica obtida através de alta temperatura em panela de pressão Pascal, por 30"' $125^{\circ} \mathrm{C}$ com Tris-Citrato pH- 7.2. Após esse período, as lâminas foram lavadas em PBS por três banhos de três minutos cada e colocadas em solução de leite em pó desnatado a 3\% (Molico). O anticorpo primário ICAM-1(CD54) (Novocastra Laboratories Lt, Newcastle, UK) título 1:80, diluído em BSA e aplicado sobre os cortes e controle positivo de tecido, e as lâminas incubadas "overnight”. As lâminas então foram lavadas em PBS e incubadas pelo NovoLink Min Polymer Detection System (Novocastra Laboratories, Newcastle, UK). Após essa etapa, as lâminas foram lavadas em PBS e seguiu-se a revelação pelo cromógeno 3,3 Diaminobenzidine (DAB) (Sigma Chemical Co, St Louis, MO, EUA). As lâminas foram lavadas abundantemente 
em água corrente e contra-coradas com Hematoxilina de Harris (Merck, Darmstadt, Alemanha). Em seguida, foram lavadas em água corrente, desidratadas, diafanizadas e montadas com resina para microscopia Entellan (Merck, Darmstadt, Alemanha).

\section{Protocolo imuno-histoquímico para reação de TUNEL "Kit” Boehringer}

Os cortes histológicos a $3 \mu \mathrm{m}$ de espessura foram realizados em lâminas silanizadas (3-Aminopropil-trietoxi-silano- Sigma) e seguiu-se o protocolo - Desparafinizar em três banhos de xilol de cinco minutos cada, sendo o $1^{\circ}$ a $60^{\circ} \mathrm{C}$ e os outros dois à temperatura ambiente, rehidratar em gradiente de etanol $(100 \%, 95 \%, 90 \%, 80 \%, 70 \%)$, Incubar em Proteinase K (Proteinas $\mathrm{K} 20 \mathrm{mg} / \mathrm{ml}$ em Tampão Tris -HCI 10mM pH 7,4) por 15-30 min à temperatura ambiente, lavar duas vezes em PBS (50 mM Fosfato + $200 \mathrm{mM} \mathrm{NaCI}$ ), Incubar em $\mathrm{H}_{2} \mathrm{O}_{2}$ 0,3\% em Metanol por 30 minutos à temperatura ambiente, lavar duas vezes em PBS, secar a área em torno da amostra, pipetar $50 \mu \mathrm{l}$ da mistura de reação TUNEL $(5 \mu \mathrm{l}$ da Solução de Enzima (tubo 1) $+45 \mu 1$ da Solução de Marcador (tubo2) por amostra, incubar as amostras sob lamínula plástica em câmara úmida a $37^{\circ} \mathrm{C}$ por 60 minutos, lavar 3vezes em PBS, secar a área em torno da amostra, pipetar 50pl do Conversor de Peroxidase (POD) por amostra, incubar as amostras sob lamínula plástica em câmara úmida a $37^{\circ} \mathrm{C}$ por 30 minutos, lavar 3vezes em PBS, pipetar $50 \mu 1$ de $\mathrm{DAB}\left(0,2 \%+\mathrm{H}_{2} \mathrm{O}_{2} 0,05 \% \mathrm{~cm} \mathrm{PBS}\right)$, incubar à temperatura ambiente por dez minutos e lavar três vezes em PBS.

\section{Protocolo Imuno-histoquímico para reação de Caspase - 3}

A imuno-histoquímica utilizada para a pesquisa do anticorpo em tecido hepático foi realizada pelo método Fosfatase Alcalina. Os cortes histológicos a $3 \mu \mathrm{m}$ de espessura foram realizados em lâminas silanizadas (3-Aminopropil-trietoxi-silano- Sigma) e seguiu-se o protocolo - as lâminas foram desparafinadas e hidratas e seguiu-se o bloqueio da peroxidade endógena com água oxigenada $\left(\mathrm{H}_{2} \mathrm{O}_{2}\right) 10 \mathrm{~V}$ $3 \%$ quatro vezes de cinco minutos cada, seguiu-se a lavagem com água e PBS (50 mM Fosfato + 200 mM NaCI); a recuperação antigênica obtida através de alta temperatura com solução de recuperação antigênica, pronta para uso, Borg Decloakercom com range de $\mathrm{pH}$ entre 9,0 a $10,0,125^{\circ}$ por $1 \mathrm{~min}$ na Panela Pascal, e lavadas em água deionizada e PBS; após os bloqueios, a Caspase 3 clivada, marca Biocare Medical, LLC. , título 1/100, e diluído em BSA foi aplicado sobre os cortes e controles, positivo de tecido, e as lâminas incubadas "overnight”. As lâminas então foram lavadas em PBS e incubadas pelo Kit MACH 2, Polímero-ALP Conjugado de cabra anti-coelho (Biocare Medical) por $30 \mathrm{~min}$ a temperatura ambiente. Após esta etapa, as lâminas foram lavadas em PBS e seguiu-se a revelação pelo cromógeno Vulcan Fast Red (Biocare Medical, EUA), por 20 a 30 min à temperatura ambiente. As lâminas foram lavadas abundantemente em água corrente e contra-coradas com Hematoxilina de Harris (Merck, Darmstadt, Alemanha). Em seguida, as mesmas foram lavadas em água corrente, desidratadas, diafanizadas e montadas com resina para microscopia Entellan (Merck, Darmstadt, Alemanha).

\section{Critérios de avaliação do HE e imuno-histoquímica}

As laminas coradas pelo HE foram analisadas duas vezes por um único patologista e os parâmetros estudados foram:

1. Classificação da esteatose hepática em macro e microvesicular e subseqüente análise semi-quantitativa, de acordo com a porcentagem de esteatose em graus leve $(<30 \%)$, moderado $(30-59 \%)$ e grave $(\geq 60 \%)$

2. Classificação do grau de exudato de neutrófilos (0 - ausente, I - raros ao redor da zona 3, II - moderado na zona 3, III acentuado nas zonas 2 e 3 )

3. Classificação do infiltrado portal linfomonoplasmocitário ( 0 - ausente, I - leve, II - moderado, III- acentuado)

4. Analise dos graus da lesão de preservação

5. Presença ou ausência de células apoptóticas

6. Presença ou ausência de fibrose portal

As laminas com marcação imuno-histoquímica para apoptose (métodos de TUNEL e caspase-3 clivada) e ICAM-1 (molécula de adesão intercelular) foram analisados por dois patologistas. Realizou-se avaliação por meio dos métodos quantitativo, de contagem de pontos (100 pontos/ campo em 10 campos), e semiquantitativo. Classificou-se em graus de acordo com a positividade da reação no parênquima hepático segundo as zonas de Rapapport em: grau I (zona III), grau II (zona II e III) e grau III (marcações desde a região centro-lobular até região peri-portal, ou seja, acometendo todo o lóbulo).

\section{Analise estatística}

Os dados foram avaliados de acordo com a natureza das variáveis. As variáveis não-paramétricas foram avaliadas através do teste de Kruskal-Wallis e as paramétricas pelo teste de A-NOVA e a sobrevivência pelas curvas de Kaplan- Meier. Os resultados foram considerados significantes quando $\mathrm{p}<0,05$.

\section{RESULTADOS}

Comparando os grupos GEL, GEM, GEG, GEA há significante diferença na sobrevivência de pacientes $(\mathrm{p}=0,05)$, em particular entre os grupos GEG vs GEA, $p=0,005$; e enxertos $(p=0,01)$; comparando GEL vs GEG obtivemos $p=0,01$ e GEG vs GEA, $\mathrm{p}=0,001$. Nas figuras 1A e 1B observam-se as curvas de sobrevivência de Kaplan- Meier.

Figura 1A - Comparação da sobrevivência de pacientes entre os grupos com esteatose leve (GEL), moderado (GEM) e grave (GEG) e ausência de esteatose (GEA).

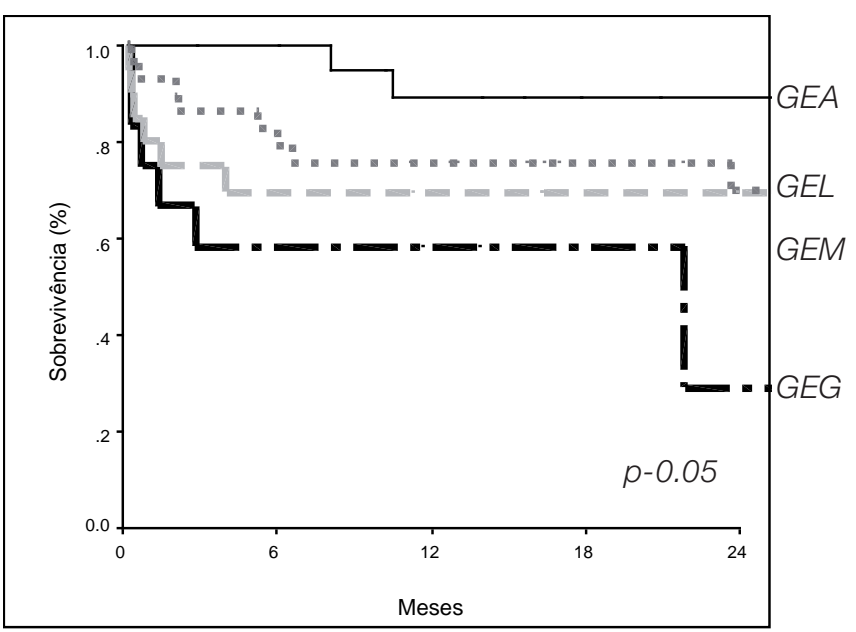


Figura 1B - Comparação da sobrevivência de enxertos entre os grupos com esteatose leve (GEL), moderado (GEM) e grave (GEG) e ausência de esteatose (GEA)

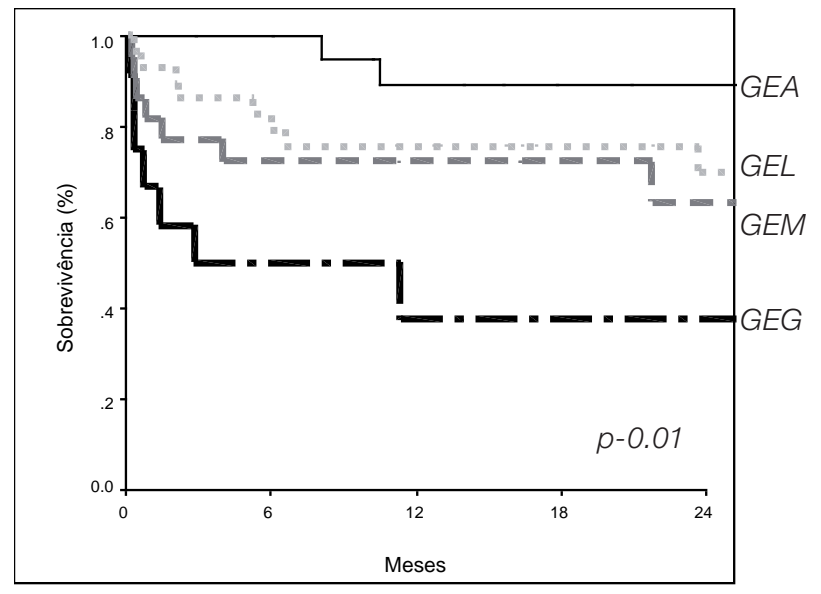

Três pacientes necessitaram um segundo TxH no período de 30 dias do transplante inicial, um por PNF e um por disfunção primária do enxerto ambos do GEG. O primeiro paciente evoluiu a óbito três anos após o retransplante devido a linfoma no enxerto e o segundo encontra-se bem $18 \mathrm{~m}$ de pós-operatório. O terceiro paciente (GEM) evoluiu com rejeição aguda córtico-resistente, foi retransplantado, porém evoluiu a óbito no pós-operatório, como consequência de choque hemorrágico. Após 60 d pós-TxH, um paciente do GEM foi retransplantado por trombose de artéria hepática, evoluindo a óbito no pós-operatório consequente a sepsis pulmonar.

As causas de óbito precoce foram: sepsis - GEL ( $n=1$ secundário disfunção primária do enxerto e $n=1$ após tratamento de rejeição celular aguda com OKT3), GEM (n-1 secundário disfunção primária do enxerto), GEG ( $\mathrm{n}=1$ secundário disfunção primária do enxerto, $\mathrm{n}=1$ trombose de veia porta, $\mathrm{n}-1$ após choque hemorrágico e múltiplas transfusões); choque hemorrágico - GEM (n=2) e abdome agudo perfurativo secundário a ulcera duodenal perfurada - GEM $(n=1)$.

Analisando exclusivamente a esteatose macrovesicular a sobrevivência de pacientes $(1,3,12 \mathrm{~m})$ comparando graus leve $(n=19)$ vs moderado mais grave $(n=9)$ vs ausência de esteatose $(n=21)$ observamos, respectivamente: $79,68,62 \%$ vs. $78,67,53 \%$ vs. $100,89 \%, p=0,02$, comparando grau leve vs ausência de esteatose, $\mathrm{p}=0,03$ e graus moderado + grave vs ausência de esteatose, $\mathrm{p}=0,008$. A sobrevivência de enxertos com macroesteatose $(1,3,12 \mathrm{~m})$ comparando graus leve $(\mathrm{n}=19)$ vs moderado mais grave (n-9) vs ausência de esteatose (n-21) observamos, respectivamente: $79,68,62 \%$ vs $67,55,42 \%$ vs $100,89 \% p=0,04$, comparando grau leve vs ausência de esteatose, $\mathrm{p}=0,03$ e grau moderado mais grave vs ausência de esteatose, $\mathrm{p}=0,006$. Posteriormente, analisando exclusivamente esteatose microvesicular, a sobrevivência de pacientes $(1,3,12 \mathrm{~m})$ comparando o grau leve $(\mathrm{n}=30)$ vs moderado+grave $(\mathrm{n}=21)$ vs ausência de esteatose (n-21) observamos, respectivamente: $93,87,77 \%$ vs. $76,67,67 \%$ vs $100,100,89 \%$, $\mathrm{p}=0,3$. A sobrevivência de enxertos com microesteatose $(1,3,12 \mathrm{~m})$ comparando o grau leve $(n=30)$ vs moderado+grave $(n=23)$ vs ausência de esteatose $(n=21)$ observamos, respectivamente: $93,87,77 \%$ vs $78,69,64 \%$ vs $100,100,89 \%$, $p=0,08$.

A principal indicação de TxH foi decorrente de doença hepática em estágio final em GEL, GEM, GEG e GEA, respectivamente: 18 (62,1\%), $15(68,2 \%), 10(83,3 \%)$ e $13(61,9 \%)$, seguido por cirrose mais tumor - $11(37,9 \%), 3(13,6 \%), 2(16,7 \%), 7(33,3 \%), p=0,6$. Três pacientes foram transplantados por insuficiência hepática aguda, sendo $2(9.1 \%)$ em GEM e $1(4.8 \%)$ do GEA e outros dois pacientes (GEM) foram submetidos a retransplante precoce. A média de tempo em lista de espera (dias) em GEL, GEM, GEG e GEA foi respectivamente de: $533,4 \pm 407,5,552,8 \pm 554,8,754,9 \pm 460,3$ e $503,3 \pm 399,9, \mathrm{p}=0,45$.

A maioria dos pacientes portadores de doença hepática crônica apresentou escore MELD entre 15 a 25 em GEL, GEM, GEG e GEA, respectivamente: $17(93,3 \%), 16(72,8 \%), 11(91,7 \%)$ e $16(76,2 \%)$, seguido pelo MELD entre 26 a 35 em 2 (6,9\%), 1 (4,5\%), 1 (8,3\%) e $3(14,3 \%)$ casos e 2 pacientes foram transplantados com MELD acima de $36=1(4,5 \%)$ em GEM e $1(4,8 \%)$ em GEA, $p=0,09$.

As médias do tempo de isquemia fria (minutos), tempo do ato intra-operatório (minutos), transfusão de concentrado de hemáceas (unidades) e tempo de internação (dias) para os grupos GEL, GEM, GEG, GEA foram respectivamente: $633,1 \pm 206,4 \mathrm{~min}$, $601,5 \pm 167,6 \mathrm{~min}, 612,0 \pm 148,3 \mathrm{~min}, 585,4 \pm 181,3 \mathrm{~min}, \mathrm{p}=0,8$; $461,8 \pm 93,5 \mathrm{~min}, 476,7 \pm 89,2 \mathrm{~min}, 426,4 \pm 83,2 \mathrm{~min}$ e $477,9 \pm 108,5 \mathrm{~min}$, $\mathrm{p}=0,5 ; 3,8 \pm 3,0 \mathrm{U}, 4,5 \pm 2,7 \mathrm{U}, 2,2 \pm 1,4 \mathrm{U}, 3,1 \pm 2,5 \mathrm{U}, \mathrm{p}=0,15$ e $18,7 \pm$ $11,6 \mathrm{~d}, 18,4 \pm 12,3 \mathrm{~d}, 32,9 \pm 38,8 \mathrm{~d}, 44,3 \pm 69,1 \mathrm{~d}, \mathrm{p}=0,09$.

Os níveis séricos de AST, ALT, gama GT, bilirrubina total, tempo de protrombina e creatinina coletados nos sete dias iniciais de pósoperatório estão representados nos gráficos de 1A a 1F. Existiu diferença significante nos níveis séricos de AST $(p=0.02)$, tempo de protrombina $(p=0,02)$ e creatinina $(p=0,04)$ no $2^{\circ}$ dia de pósoperatório. A diferença estatística se mantém para creatinina do $2^{\circ}$ ao $7^{\circ}$ dia pós-transplante.

Gráficos 1A a 1F - Comparação entre os grupos com esteatose leve, moderada, grave e ausente, dos níveis séricos de AST, ALT, bilirrubina total, Gama GT, tempo de protrombina e creatinina nos 7 dias iniciais póstransplante hepático.
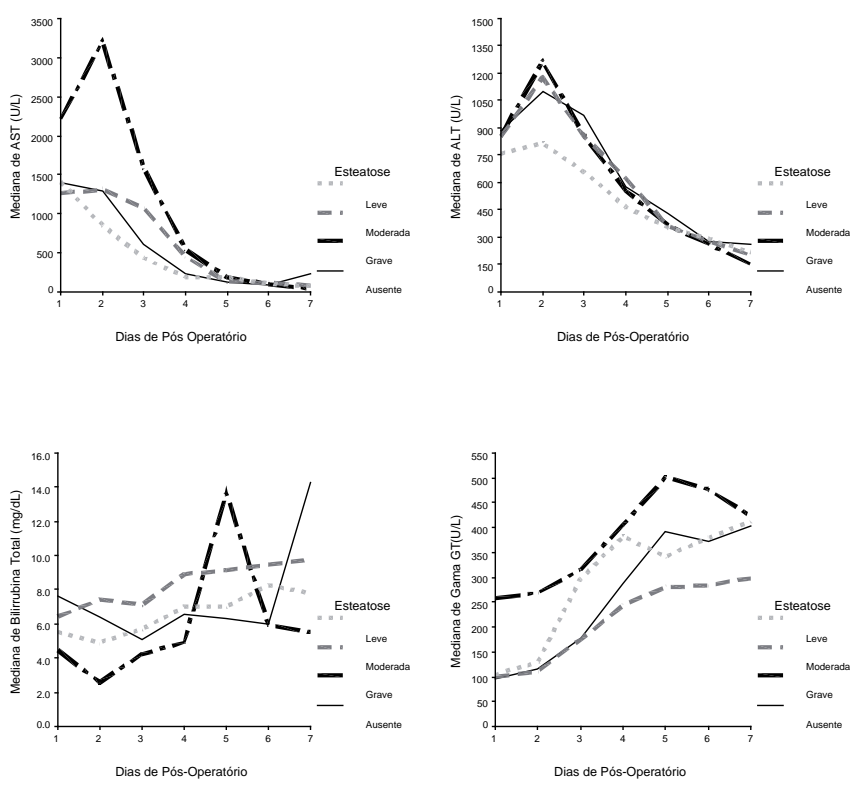

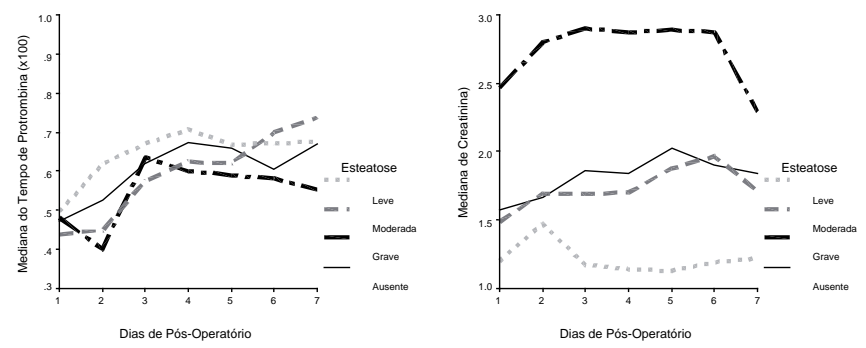

\section{Análise semi-quantitativa das biópsias hepáticas (HE)}

As biópsias pré e pós-reperfusão arterial coradas por HematoxilinaEosina (HE) foram avaliadas, e foi realizada análise semiquantitativa do grau de esteatose macro e microvesicular. Assim macroesteatose grau leve foi observada em GEL- 8 (27.6\%), GEM- 7 (31.8\%), GEG - 4 (33.3\%) e GPR- $3(16.6 \%)$ e os graus moderado mais grave em GEM - 5 (22.7\%), GEG - 4(33.3\%) e GPR -2 (11.1\%). Identificou-se esteatose microvesicular grau leve em 24 (83\%) - GEL, 4 (18\%) - GEM, 2 (17\%)- GEG e 2 (11.1\%)GPR e os graus moderado mais severo em 15 (68\%) - GEL, 8 (67\%) -GEG e 4 (22.2\%)- GPR. Há significante diferença entre os grupos, comparando os graus de exudato de neutrófilos e a presença de lesão de preservação. Os demais parâmetros analisados através de HE estão na tabela 01. Todos os parâmetros da tabela 01 foram analisados para os grupos de esteatose macrovesicular e microvesicular, não tendo sido observada diferença significante.

Tabela 01 - Análise semi-quantitativa dos graus de exudato de neutrófilos, lesão de preservação e infiltrado portal linfomonoplasmocitário, presença de células apoptóticas e fibrose portal, comparando os grupos com esteatose leve, moderada, grave, ausente e pré- reperfusão.

\begin{tabular}{|c|c|c|c|c|c|c|}
\hline Grupos & $\begin{array}{c}\text { GEL } \\
(n-29)\end{array}$ & $\begin{array}{r}\text { GEM } \\
(n-22)\end{array}$ & $\begin{array}{l}\text { GEG } \\
(n-12)\end{array}$ & $\begin{array}{l}\text { GEA } \\
(n-21)\end{array}$ & $\begin{array}{c}\text { GPR } \\
(n-18)\end{array}$ & $p$ \\
\hline $\begin{array}{l}\text { Exudato de } \\
\text { Neutrófilos }\end{array}$ & & & & & & \multirow{5}{*}{0.01} \\
\hline Ausente & $3(10.3 \%)$ & 0 & $1(8.3 \%)$ & 2 (9.5\%) & $3(16.7 \%)$ & \\
\hline Grau 1 & $15(51.7 \%)$ & $10(45.5 \%)$ & $1(8.3 \%)$ & 9 (42.9\%) & $12(66.7 \%)$ & \\
\hline Grau 2 & $6(20.7 \%)$ & $4(18.2 \%)$ & $6(50 \%)$ & $3(14.3 \%)$ & 2 (11.1\%) & \\
\hline Grau 3 & $5(17.2 \%)$ & $8(36.4 \%)$ & $4(33.3 \%)$ & 7 (33.3\%) & $1(5.6 \%)$ & \\
\hline $\begin{array}{l}\text { Lesão } \\
\text { preservação } \\
\text { Ausente } \\
\text { Grau 1 } \\
\text { Grau 2 } \\
\text { Grau 3 }\end{array}$ & $\begin{array}{c}24(82.8 \%) \\
5(17.2 \%) \\
0 \\
0\end{array}$ & $\begin{array}{c}16(72.7 \%) \\
3(13.6 \%) \\
1(4.5 \%) \\
2(9.1 \%)\end{array}$ & $\begin{array}{c}7(58.3 \%) \\
3(25 \%) \\
1(8.3 \%) \\
1(8.3 \%)\end{array}$ & $\begin{array}{c}18(85.7 \%) \\
1(4.8 \%) \\
1(4.8 \%) \\
1(4.8 \%)\end{array}$ & $\begin{array}{c}16(100 \%) \\
0 \\
0 \\
0\end{array}$ & 0.04 \\
\hline $\begin{array}{r}\text { Infiltrado Portal } \\
\text { Ausente } \\
\text { Grau } 1 \\
\text { Grau } 2\end{array}$ & $\begin{array}{c}13(44.8 \%) \\
14(48.3 \%) \\
2(6.9 \%)\end{array}$ & $\begin{array}{c}6(27.3 \%) \\
13(59.1 \%) \\
3(13.6 \%)\end{array}$ & $\begin{array}{l}4(33.3 \%) \\
4(33.3 \%) \\
4(33.3 \%)\end{array}$ & $\begin{array}{c}8(38 \%) \\
10(48 \%) \\
3(14 \%)\end{array}$ & $\begin{array}{l}8(44.4 \%) \\
7(38.9 \%) \\
3(16.7 \%)\end{array}$ & 0.6 \\
\hline $\begin{array}{l}\text { Apoptose } \\
\quad \text { presente }\end{array}$ & $11(37.9 \%)$ & $13(59.1 \%)$ & $8(66.7 \%)$ & 11 (53\%) & $5(28 \%)$ & 0.20 \\
\hline $\begin{array}{l}\text { Fibrose portal } \\
\text { presente }\end{array}$ & $1(3.4 \%)$ & $1(4.5 \%)$ & $1(8.3 \%)$ & $4(19 \%)$ & $3(16.7 \%)$ & 0.3 \\
\hline
\end{tabular}

GEL- grupo de esteatose leve, GEM - grupo de esteatose moderada, GEG - grupo de esteatose grave, GEA - grupo de esteatose ausente, GPR grupo pré- reperfusão.

\section{Analise semi-quantitativa da apoptose e ICAM-1}

$\mathrm{Na}$ analise semi-quantitativa da apoptose (método de TUNEL) e do ICAM-1 não existiu diferença significante, comparando os locais de comprometimento das células em apoptose ou expressando o ICAM-1. Nas figuras 2 e 3 podemos observar o comprometimento das células ao redor da veia centro-lobular.

Na tabela 02 estão os resultados dessa análise. Também não existiu diferença estatística analisando isoladamente os grupos com esteatose micro e macrovesicular.

Figura 2 - Comparação entre os grupos GEL, GEM, GES,GEA observando na região da veia centro-lobular marcação pelo ICAM-1

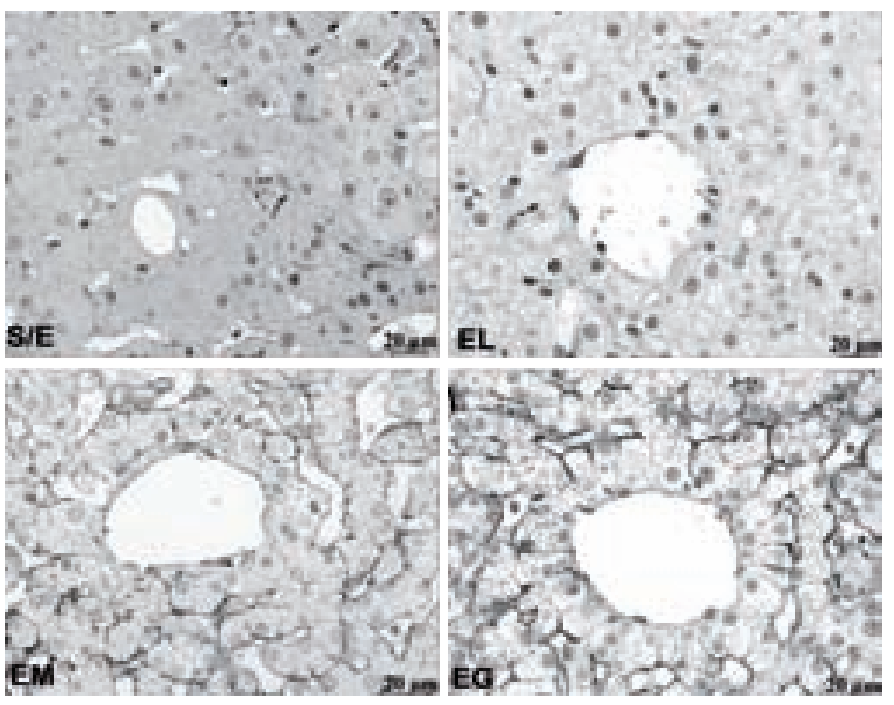

Figura 03 - Comparação entre os grupos GEL, GEM, GEG, GEA, as células em apoptose ao redor da veia centro-lobular (método de TUNEL)
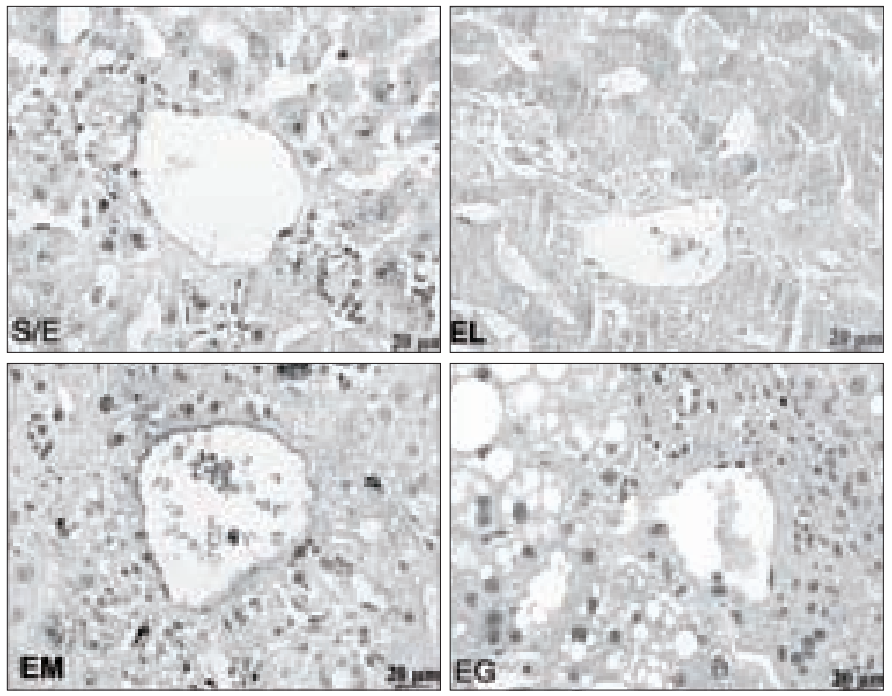
Tabela 02 - Comparação entre os grupos de esteatose leve, moderada, severa e ausente e o grupo pré-reperfusão referente ao local de comprometimento das células intra-hepáticas por apoptose e por ICAM-1 e a extensão desse processo no parênquima.

\begin{tabular}{|c|c|c|c|c|c|c|}
\hline Grupos & $\begin{array}{c}\text { GEL } \\
(\mathrm{n}-23)\end{array}$ & $\begin{array}{c}\text { GEM } \\
(\mathrm{n}-22)\end{array}$ & $\begin{array}{c}\text { GEG } \\
(\mathrm{n}-12)\end{array}$ & $\begin{array}{c}\text { GEA } \\
(\mathrm{n}-19)\end{array}$ & $\begin{array}{c}\text { GPR } \\
(n-17)\end{array}$ & $p$ \\
\hline $\begin{array}{l}\text { Local de } \\
\text { apoptose } \\
\text { ausente } \\
\text { Zona } 3 \\
\text { Zona } 3 \text { a } 2 \\
\text { Zona } 3 \text { a } 1\end{array}$ & $\begin{array}{c}1(4.3 \%) \\
3(10.3 \%) \\
2(8.7 \%) \\
17(73.9 \%)\end{array}$ & $\begin{array}{c}1(4.5 \%) \\
2(9.1 \%) \\
2(9.1 \%) \\
17(77.3 \%)\end{array}$ & $\begin{array}{c}1(8.3 \%) \\
2(16.7 \%) \\
2(16.7 \%) \\
7(58.3 \%)\end{array}$ & $\begin{array}{c}0 \\
3(15.8 \%) \\
3(15.8 \%) \\
1368.4 \%)\end{array}$ & $\begin{array}{c}4(23.5 \%) \\
1(5.9 \%) \\
2(11.8 \%) \\
10(58.8 \%)\end{array}$ & 0.6 \\
\hline $\begin{array}{l}\text { Acometimento } \\
\text { apoptose } \\
\text { Ausente } \\
\text { Difuso } \\
\text { Focal }\end{array}$ & $\begin{array}{c}1(4.3 \%) \\
14(60.9 \%) \\
8(34.8 \%)\end{array}$ & $\begin{array}{c}1(4.5 \%) \\
12(54.5 \%) \\
9(40.9 \%)\end{array}$ & $\begin{array}{c}1(8.3 \%) \\
5(41.7 \%) \\
6(50 \%)\end{array}$ & $\begin{array}{c}0 \\
10(52.6 \%) \\
9(47.4 \%)\end{array}$ & $\begin{array}{l}4(23.5 \%) \\
6(35.3 \%) \\
7(41.2 \%)\end{array}$ & 0.8 \\
\hline $\begin{array}{r}\text { Local de ICAM-1 } \\
\text { ausente } \\
\text { Zona } 3 \\
\text { Zona } 3 \text { a } 2 \\
\text { Zona } 3 \text { a } 1\end{array}$ & $\begin{array}{c}5(21.7 \%) \\
6(26.1 \%) \\
1(4.3 \%) \\
11(47.8 \%)\end{array}$ & $\begin{array}{c}6(27.3 \%) \\
4(18.2 \%) \\
2(9.1 \%) \\
10(45.5 \%)\end{array}$ & $\begin{array}{c}0 \\
2(16.7 \%) \\
0 \\
10(83.3 \%)\end{array}$ & $\begin{array}{c}3(15.8 \%) \\
5(26.3 \%) \\
1(5.3 \%) \\
10(52.6 \%)\end{array}$ & $\begin{array}{c}1(5.9 \%) \\
2(11.8 \%) \\
1(5.9 \%) \\
13(76.5 \%)\end{array}$ & 0.06 \\
\hline $\begin{array}{l}\text { Acometimento } \\
\text { ICAM-1 } \\
\text { Ausente } \\
\text { Difuso } \\
\text { Focal }\end{array}$ & $\begin{array}{c}5(21.7 \%) \\
4(17.4 \%) \\
14(60.9 \%)\end{array}$ & $\begin{array}{l}6(27.3 \%) \\
7(31.8 \%) \\
9(40.9 \%)\end{array}$ & $\begin{array}{c}0 \\
7(58.3 \%) \\
5(41.7 \%)\end{array}$ & $\begin{array}{c}3(15.8 \%) \\
4(21.1 \%) \\
12(63.2 \%)\end{array}$ & $\begin{array}{c}1(5.9 \%) \\
7(41.2 \%) \\
9(52.9 \%)\end{array}$ & 0.6 \\
\hline
\end{tabular}

GEL- grupo de esteatose leve, GEM - grupo de esteatose moderada, GEG - grupo de esteatose grave, GEA - grupo de esteatose ausente, GPR grupo pré- reperfusão.

\section{Analise quantitativa de apoptose (método de TUNEL)}

A média do índice de apoptose para os grupos 1- GEL (n-23), 2-GEM(n-22), 3- GEG(n-12), 4- GEA(n-19) e 5-GPR(n-17), foi respectivamente: de $0.262 \pm 0.111,0.278 \pm 0.113,0.244 \pm 0.117$, $0,275 \pm 0.094$ e $0.181 \pm 0.123, p-0.07$, conforme observado no gráfico 2A. Entretanto, ao analisarmos isoladamente o grupo macroesteatose, observamos diferença estatística referente à média do índice de apoptose entre graus de esteatose leve- G1 (n-21), moderada mais severa - G2+3 (n-11) e grupo sem esteatose- G4 (n-19). A média do índice de apoptose nos grupos 1, 2+3, 4 foi respectivamente de: $0.284 \pm 0.106,0.160 \pm 0.109,0,275 \pm 0.094, \mathrm{p}-0.05$, comparando G1 vs G2+3, p-0.02 e G2+3 vs G4, p-0.03, gráfico 2 B. Analisando isoladamente o grupo microesteatose, a média do índice de apoptose entre os graus de esteatose leve- G1 (n-27), moderada mais severa - G2+3 (n-26) e grupo sem esteatose- G4 (n19) foi respectivamente de: $0.222 \pm 0.123,0.293 \pm 0.108,0.275 \pm 0.094$, p-0.049, comparando G1 vs G2+3, p-0.04, gráfico 2 C.

Gráfico 2 A - Comparação das médias do índice de apoptose entre os grupos 1-GEL, 2-GEM, 3-GEG, 4-GEA, 5-GPR

Gráfico 2 B - Comparando as médias do índice de apoptose no grupo de macroesteatose em diferentes graus de esteatose- leve (G1), moderada mais severa (G2+3) e sem esteatose (G4)
Gráfico 2 C - Comparando as médias do índice de apoptose no grupo de microesteatose em diferentes graus de esteatose- leve (G1), moderada mais severa $(G 2+3)$ e sem esteatose (G4).
Gráfico $2 A$

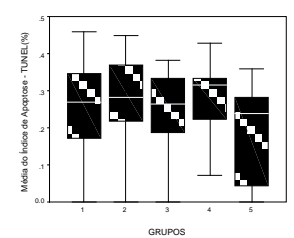

GRupos
Gráfico 2 B

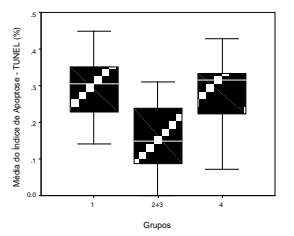

Gráfico 3 C

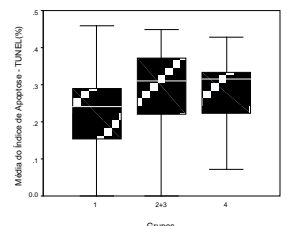

Analise quantitativa de apoptose (método de Caspase-3)

A média do índice de apoptose (método de Caspase-3) para os grupos 1- GEL (n-23), 2-GEM(n-22), 3- GEG(n-12), 4- GEA(n-19) e 5-GPR(n-17), foi respectivamente de: $G E L=0,126 \pm 0,146$, $\mathrm{GEM}=0,118 \pm 0,09, \mathrm{GEG}=0,167 \pm 0,128, \mathrm{GEA}=0,110 \pm 0,09 \mathrm{eGPR}=$ $0,204 \pm 0,146, p-0.4$,conforme observado no gráfico $3 \mathrm{~A}$. Ao analisarmos isoladamente o grupo macroesteatose, a média do índice de apoptose entre graus de esteatose leve- G1 (n-21), moderada mais severa - G2+3 (n-11) e grupo sem esteatose- G4 (n-19) foi de: $\mathrm{G} 1=0,154 \pm 0,125, \mathrm{G} 2+3=0,152 \pm 0,149, \mathrm{G} 4=0,110 \pm 0.09$, p-0,6. A média do índice de apoptose no grupo microesteatose comparando entre os graus de esteatose leve- G1 (n-27), moderada mais severa - G2+3 (n-26) e grupo sem esteatose- G4 (n-19) foi de $\mathrm{G} 1=0,122 \pm 0,138, \mathrm{G} 2+3=0,146 \pm 0,09, \mathrm{G} 4=0,110 \pm 0,09, \mathrm{p}-0.7$.

Gráfico $3 \boldsymbol{A}$ - Comparação das médias do índice de apoptose entre os grupos 1-GEL, 2-GEM, 3-GEG, 4-GEA, 5-GPR

Gráfico 3 B - Comparação das médias do índice de apoptose no grupo de macroesteatose em diferentes graus de esteatose- leve (G1), moderada mais severa $(G 2+3)$ e sem esteatose (G4)

Gráfico 3 C - Comparação das médias do índice de apoptose no grupo de microesteatose em diferentes graus de esteatose- leve (G1), moderada mais severa (G2+3) e sem esteatose (G4).
Gráfico 3 A

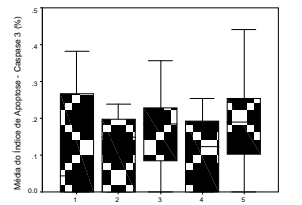

Grupos
Gráfico 3 B

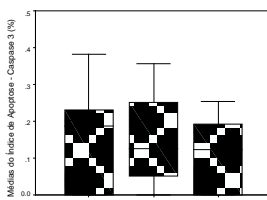

Grupos
Gráfico 3 C

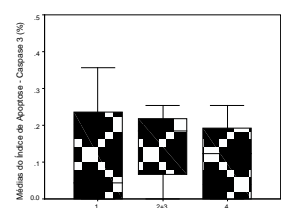

Grnos

\section{Analise quantitativa do ICAM-1}

A média do índice de ICAM-1 foi para os grupos 1- GEL (n23), 2-GEM(n-22), 3- GEG(n-12), 4- GEA(n-19) e 5-GPR(n-17), respectivamente: $0.210 \pm 0.152,0.217 \pm 0.183,0.317 \pm 0.139$, $0.208 \pm 0.146$ e $0.234 \pm 0.118$, p- 0.4 , conforme observado no gráfico 4A. Ao analisarmos isoladamente o grupo macroesteatose, a média do índice de ICAM-1 entre os graus de esteatose leve-G1 (n-21), moderada mais severa - G2+3 (n-11) e grupo sem esteatose- G4 (n- 
19) foi respectivamente de: $0.236 \pm 0.153,0.229 \pm 0.119,0.208 \pm 0.146$, p-0.8, gráfico 4B. Para o grupo microesteatose, a média do índice de ICAM-1 entre os graus de esteatose leve- G1 (n-27), moderada mais severa - G2+3 (n-26) e grupo sem esteatose- G4 (n-19) foi respectivamente: $0.193 \pm 0.149,0.280 \pm 0.175,0.208 \pm 0.146, \mathrm{p}-0.1$, gráfico 4C. Entre os grupos não existiu diferença estatística.

Gráfico 4A - Comparação das médias do índice de ICAM-1 entre os grupos 1-GEL, 2-GEM, 3-GEG, 4-GEA, 5-GPR

Gráfico 4B - Comparação das médias do índice de ICAM-1 no grupo de macroesteatose em diferentes graus de esteatose- leve (G1), moderada mais severa $(G 2+3)$ e sem esteatose (G4)

Gráfico 4C - Comparação das médias do índice de ICAM-1 no grupo de microesteatose em diferentes graus de esteatose- leve (G1), moderada mais severa $(\mathrm{G} 2+3)$ e sem esteatose (G4).
Gráfico $4 \mathrm{~A}$

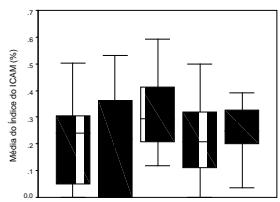

Gupos
Gráfico 4 B

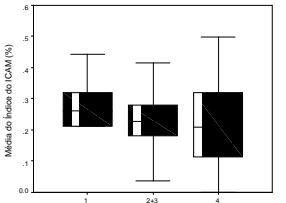

Guress
Gráfico 4 C

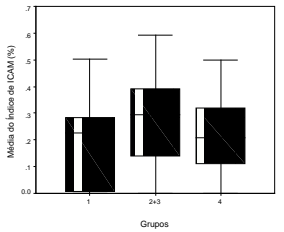

\section{DISCUSSÃO}

A presença de esteatose nos enxertos hepáticos está associada ao aumento de não funcionamento primário do enxerto (PNF), necessidade de re-transplante e diminuição na sobrevivência dos receptores no primeiro ano pós-transplante (67-69\% vs. 86$87 \%$ ). ${ }^{4,13,14}$ Os enxertos hepáticos com 30 a $60 \%$ de esteatose são classificados como sub-ótimos, por aumentarem o risco de PNF, 6,18,19 porém são transplantados em pacientes sem fatores de riscos adicionais ou em situações críticas no qual se justifica enfrentar tais ris $\cos ^{20}$. Com o aumento da demanda de enxertos para transplante, muitos centros têm utilizado fígados com esteatose moderada e grave. ${ }^{21}$ No nosso estudo, a presença de algum grau de esteatose nos enxertos transplantados foi de aproximadamente $75 \%$, sendo $26 \%$ moderado e $14 \%$ de grau grave. A incidência de PNF foi de $1.2 \%(1 / 84) \mathrm{TxH}$, no grupo com esteatose macrovesicular grave; porém, a disfunção primária do enxerto ocorreu em 5\% (4/84) dos pacientes (1- GEL, 1- GEM e 2 - GEG): 2 deles evoluíram a óbito secundário a sepsis e 1 consequente a edema cerebral. Um paciente do GEG foi retransplantado e encontra-se bem 18 meses após o TxH.

Enquanto a esteatose macrovesicular aumenta a incidência de PNF em 5,1\% comparado a 1,8\% dos enxertos sem esteatose e diminui a sobrevivência de pacientes (77\% versus $91 \%$ ) daqueles sem esteatose e enxertos $(70 \%$ versus $82 \%),{ }^{17}$ a microesteatose apresenta resultados similares aos dos enxertos sem esteatose. ${ }^{15,16}$ Esses achados também foram observados no nosso estudo, onde a análise exclusiva de macroesteatose diminuiu significantemente a sobrevivência de pacientes e enxertos quando comparados ao grupo sem esteatose. Já a presença exclusiva de esteatose microvesicular não apresentou impacto na sobrevivência de pacientes e enxertos, independentemente do grau de esteatose.
Atualmente, medidas terapêuticas têm sido investigadas, a fim de vencermos os desafios da esteatose no transplante hepático e assim, expandir os critérios para utilização daqueles enxertos. ${ }^{22,33}$ Os achados histológicos atribuídos à lesão de IF/RQ incluem a presença de esteatose microvesicular, infiltrados focais de neutrófilos no parênquima hepático, colestase, balonização dos hepatócitos, necrose e apoptose ${ }^{40}$ e são fatores preditivos da função dos enxertos..$^{39,41,42,43}$ No presente estudo, observamos que $83 \%$ dos enxertos com esteatose grave apresentaram algum grau de exsudato de neutrófilos e em $42 \%$ identificamos a presença de lesão de preservação.

Apesar da média do índice de apoptose não ser estatisticamente significante entre os grupos GEL vs GEM vs GEG vs GEA, o grupo GEG apresentou menor índice de apoptose em relação aos demais. Achados similares foram observados quando analisamos exclusivamente o grupo macroesteatose, no qual os graus moderado e severo apresentaram significante redução no índice de apoptose. Esses achados podem estar relacionados ao fato das células com esteatose macrovesicular, em graus moderado e grave, não iniciarem o processo de apoptose, mas sim evoluirem diretamente à necrose. Já a esteatose microvesicular em graus moderado e grave apresentaram significante aumento no índice de apoptose, provavelmente relacionado à lesão de isquemia e reperfusão. Quanto maior o grau de lesão de IF/RQ, maior será a presença de microesteatose e consequentemente maiores índices de apoptose.

As médias do índice de ICAM-1 não foram significantes entre os grupos GEL vs GEM vs GEG vs GEA, porém, o grupo com esteatose grave apresentou média maior do que os demais. No grupo microesteatose (graus moderado e grave), também se observou aumento nos índices de ICAM-1. Esses índices não apresentaram significância, provavelmente, pelo reduzido número de componentes da amostra. Esses achados sugerem que o ICAM1 participa da lesão de IF/RQ na esteatose grave, principalmente na microesteatose.

Os níveis séricos de AST, tempo de protrombina e creatinina elevaram-se mais no $2^{\circ}$ dia pós-operatório no grupo GEG e a creatinina manteve-se elevada até o $7^{\circ}$ pós-operatório, podendo ter refletido a disfunção dos enxertos.

\section{CONCLUSÃO}

Neste estudo, a presença de esteatose nos enxertos transplantados foi observada em $75 \%$ dos casos. Apesar de $40 \%$ dos enxertos apresentarem mais do que $30 \%$ de esteatose, a incidência de PNF e disfunção primária do enxerto foi de $1.2 \%$ e $5 \%$. Também observamos no nosso estudo que a macroesteatose diminuiu significantemente a sobrevivência de pacientes e enxertos quando comparadas ao grupo sem esteatose. A presença exclusiva de esteatose microvesicular não apresentou impacto na sobrevivência de pacientes e enxertos, independentemente do grau de esteatose.

O grupo GEG e o grupo macroesteatose (graus moderado e severo) apresentaram significante redução no índice de apoptose. Esses achados podem estar relacionados ao fato de que as células com esteatose macrovesicular, em graus moderado e grave não iniciam o processo de apoptose, mas sim o de necrose.

Já a esteatose microvesicular em graus moderado e grave apresentaram significante aumento no índice de apoptose, 
provavelmente relacionado à lesão de isquemia e reperfusão. Quanto maior o grau de lesão de IF/RQ, maior será a presença de microesteatose e, consequentemente, maiores índices de apoptose. Porém, o grupo com esteatose grave apresentou média maior do que os demais.

Nos grupos microesteatose (graus moderado e grave) e GEG observou-se aumento nos índices de ICAM-1. Esses índices não apresentaram significância, provavelmente, pelo reduzido número de componentes da amostra. Esses achados sugerem que o ICAM1 participa da lesão de IF/RQ na esteatose grave, principalmente na microesteatose.

Os resultados deste estudo permitem que futuras pesquisas e estratégias sejam desenvolvidas, com o objetivo de modular a lesão de isquemia e reperfusão nos enxertos com e sem esteatose e, consequentemente, seja possível expandir o número de enxertos disponíveis.

\section{ABSTRACT}

Introduction: Many factors are responsible for the ischemic/reperfusion injury in liver transplants, such as apoptosis. However, the role of ischemic/reperfusion injury in steatotic grafts is still unclear. Purpose: to analyze the role of ischemic/reperfusion injury in liver transplant comparing steatotic vs non-steatotic graft. Patients and Methods: Between May/02 and march/07, 84 liver biopsies (2hours) were performed after arterial reperfusion of grafts. It was performed an amount of 84 liver transplants in 82 patients. Liver biopsies were divided in 5 groups, according to the degree of macro and microvesicular steatosis in: mild ( $<30 \%)$-MSG, moderate $(30-59 \%)$-MoSG, severe $(\geq 60 \%)$ - SSG, and absent stetatosis - ASG before reperfusion - BRG. 102 liver biopsies analyzed: the percentage of macro and micro steatosis, neutrophils infiltration degree, apoptosis index (TUNEL and Caspase-3) and ICAM-1. Also, it was analyzed the macro and micro steatosis alone, which were ranked in different degrees: mild (G1), moderate (G2), severe (G3) and absent (G4). Results: The apoptosis index (TUNEL) was: $\mathrm{MSG}=0.262 \pm 0.111, \mathrm{MoSG}=0.278 \pm 0.113, \mathrm{SSG}=0.244 \pm 0.117, \mathrm{ASG}=0,275 \pm 0.094$ e $\mathrm{BPR}=0.181 \pm 0.123, \mathrm{p}-0.07$. The macrosteatosis' apoptosis index (TUNEL) was G1 $=0.284 \pm 0.106, \mathrm{G} 2+3=0.160 \pm 0.109$, G4 $=0,275 \pm 0.094$, p- 0.05 ; and the microsteatosis group - G1 $=0.222 \pm 0.123, \mathrm{G} 2+3=0.293 \pm 0.108$, G4 $=0.275 \pm 0.094$, p- 0.049 . There was no statistic difference between groups when analyzing the apoptosis (caspase-3) and ICAM-1 index. Conclusion: The severe steatotic and macrosteatosis groups (degree moderate and severe) presented a significant decrease in the apoptosis index, probably because those cells died before starting the apoptotic process. However, the microsteatosis group (degree moderate and severe) increased the apoptotic index associated to the ischemic/reperfusion injury.

Keywords: Ischemia, Reperfusion, Transplantation, Liver, Apoptosis, ICAM-1

\section{REFERÊNCIAS}

1. Consensus Conference on indications of liver transplantation.Hepatology 1994,20:1S-68S

2. Neuberger J. Liver transplantation. J Hepatolog. 2000;32 (suppl 1):198-207

3. Strong RW. Liver transplantation: current status and future prospects. JR Coll Surg Endimb. 2001;46:1-8

4. Liver Transplant Waiting List. UNOS database 2000. http//www.optn.org/J URL.

5. Fishbein TM, Fiel MI, Emre S, Cubukru O, Guy SR, et al. Use of livers with microvesicular fat safely expands the donor pool. Transplantation. 1997;64:248-51

6. Selzner M, Clavien PA. Fatty liver in liver transplantation and surgery. Semin Liver Dis. 2001;21:105-13

7. Rinella ME, Alonso E, Rao S, et al. Body mass index as a predictor of hepatic stetatosis in living liver donors. Liver Transpl. 2001;7:409-14

8. Levensky NG. Organ donation by unrelated donors. N Engl J Med. 2000;343:430-2

9. Imber CJ, St Peter SD,Lopez I, et al. Current practice regarding the use of fatty livers: a trans-atlantic survey. Liver Transpl. 2002;8:545-9

10. Fiorini RN, Shafizadeh SF, Polito C, Rodwell DW, et al. Am J Transplant. 2004;4:1567-73

11. Ryan C, Johnson LA, GerminBI, et al. One hundred consecutive hepatic biopsies in the workup of living donors for right lobe liver transplantation. Liver Transpl. 2002;8:1114-22

12. Kamal M, Lassman CR, Ghobrial RM, Saab S, Marks K et al. Histologic findings in potential living liver donors biopsies. Hepatology. 2003;38:650A (abstract)
13. Burke A, Lucey MR. Non-alcoholic fatty liver disease, non-alcoholic fatty steatohepatitis and orthotopic liver transplantation. Am J Transplant. 2004;4:686-93

14. Watt KDS, Lyden ER, McCashlandTM. Poor survival after liver retransplantation: is hepatitis C to blame. Liver Transpl. 2003;9:1019-24

15. Bessems M, Doorschodt BM, van Vliet AK, et al. Improved rat liver preservation by hypothermic continuous machine perfusion using polysol, a new, enriched preservation solution. Liver Transpl. 2005;11,539-46

16. Boudjema K, Lindell SL, Belzer FO, et al. Effects of methods of preservation on functions of livers from fed and fast rabbits. Cryobiology. 1991;28:227-36

17. Marsman WA, Wiesner RH, Rodrigues $L$ et al. Use of fatty donor liver is associated with diminished early patient and graft survival. Transplantation. 1996;62:1246-51

18. Busquets J, Figueras J, Serrano T, Torras J, Ramos E, et al. Postreperfusion biopsies are useful in predicting complications after liver transplantation. Liver Transpl. 2001;7:432- 5

19. Busquets J, Serrano T, Figueras J, Ramos E et al. Influence of donor post- reperfusion changes on graft evolution after liver transplant. Rev Esp Enferm Dig 2001;93:39-47

20. Urena NA, Moreno GE, Romero CJ, et al. An approach to the rational use of steatotic donor livers in liver transplantation. HepatoGastroenterology 1999; 46:1164-73.

21. Salizzoni M, Franchello A, Zamboni F et al. Marginal grafts: finding the correct treatment of fatty livers. Transpl Int. 2003;16:486-93

22. Imber CJ, St Peter SD,L Handa A, Friend PJ. Hepatic steatosis and its relationship to transplantation. Liver Transpl. 2002;8:415-23 
23. Hui AM, Kawasaki S, Makuuchi M et al. Liver injury following normothermic ischemia in steatotic rat liver. Hepatology. 1994;20:1287-93

24. Wada K, Fujimoto K, Fujikawa Y, et al. Sinusoidal stenosisas the cause of portal hypertension in choline deficient diet induced fatty cirrhosis of the rat liver. Acta Pathol Japon. 1974;24:207-17

25. Chavin KD, Yang SQ, Lin HZ et al. Obesity induces expression of uncoupling protein-2 in hepatocytes and promotes liver ATP depletion. J Biol Chem. 1999;274:5692-700

26. Cortez-Pinto H, Lin HZ, Yang SQ, Da Costa SO, et al. Lipids upregulate uncoupling protein 2 expression in rat hepatocytes. Gastroenterology. 1999;116:1184-93

27. Cisnero C, Guillen F, Gomes R et al. Analysis of warm ischaemia time for prediction of primary nonfunction of hepatic graft. Transplant Int. 1991;23:1976

28. Fukumori T, Ohkohchi N, Tsukamoto S, Satomi S. The mechanism of injury in a steatotic liver graft during cold preservation. Transplantation. 1999;67:195-200

29. Todo S, DeMetris AJ, Makowha L et al. Primary nonfunction of hepatic allografts with preexisting fatty infiltration. Transplantation 1989; 47:903-905

30. Letteron P, Fromenty B, Thomas P et al. Acute and chronic hepatic steatosis lead to in vivo lipid peroxidation in mice. J Hepatol. 1996;24:200-8

31. Laight DW, Desai KM, Gopaul NK, et al. F2-isoprostane evidence of oxidant stress in the insulin resistant, obese Zucker rat: effects of vitamin E. Eur J Pharmacol. 1999;377:89-92

32. Soltyl K, Dikdan G, Koneru B. Oxidative stress in fatty livers of obese Zucker rats: rapid amelioration and improved tolerance to warm ischemia with tocopherol. Hepatology. 2003;34:13-8

33. Tekin K, Imber CJ, Atli M, et al. A simple scoring system to evaluate the effects of cold ischemia on marginal liver donors. Transplantation. 2004;77:411-6

34. Fellstrom B, Akuyrek LM, Bachman U, Larsson E, et al. Postischemic reperfusion injury and allograft arteriosclerosis. Transplant Proc. 1998; 30:4278-80

35. Belser FO, Southard JH. Principles of solid-organ preservation by cold storage Transplantation. 1988;45:673-6

36. Kang KJ. Mechanism os hepatic ischemia/reperfusion injury and protection against reperfusion injury. Transplant Proc. 2002;34:2659-61

37. Kupiec-Weglinski JW, Busuttil RW. Ischemia and reperfusion injury in liver transplantation. Transplant Proc. 2005;37:1653-6

38. Bzeize KL, Jalan R, Plevris JN, Hayes PC. Primary graft dysfunction after liver transplantation: from pathogenesis to prevention. Liver Transpl Surg. 1997,3:137-48

39. Bao YM, Adam R, Sebagh M, Reynes M, et al. Risk factors of preservation injury and prognostic value of reperfusion biopsy in outcome of liver transplantation. Transplant Proc. 1996;28:123-4

40. Neil DA, Hubscher SG. Are parenchymal changes in early post-transplant biopsies related to preservation-reperfusion injury or rejection? Transplantation. 2001;71:1566-72
41. Kakizoe S, Yanaga K, Starzl T, et al. Evaluation of protocol before transplantation and after reperfusion biopsies from human orthotopic liver allografts: considerations of preservation and early immunological injury. Hepatology. 1990;11:932-41

42. Clavien PA, Harvey PR, Strasberg SM. Preservation and reperfusion injury in liver allografts. An overview and synthesis of current studies. Transplantation. 1992;53:957-78

43. D'Alessandro AM, Kalayoglu M, Sollinger HW,et al. The predictive value of donor liver biopsies on development of primary nonfunction after orthotopic liver transplantation. Transplant Proc. 1991;23:1536-7

44. Sindram D, Porte RJ, Hoffman MR, et al. Platelets induce sinusoidal endothelial cell apoptosis upon reperfusion of cold ischemic rat liver. Gastroenterology. 2000;118:183-91

45. Kohli V, Selzner M, Madden JF, et al. Endothelial cell and hepatocyte deaths occur by apoptosis after ischemia-reperfusion injury in the rat liver. Transplantation. 1999;67:1099-105

46. Kuo PC, Drachenberg CI, de la Torre A et al. Apoptosis and hepatic allograft reperfusion injury. Clin Transplant .1998;12:219-23

47. Borghi-Scoazec G, Scoazec JY, Durand F et al. Apoptosis after ischemia-reperfusion injury in human liver allografts. Liver Transpl Surg. 1997;3:407-15

48. Danial NN, Korsmeyer SJ. Cell death: critical control points. Cell. 2004;116:205-19

49. Selzner N, Rudiger H, Graf R, et al. Protective strategies againts ischemic injury of the liver. Gastroenterology. 2003;125:917-36

50. Rudiger HA, Graf R, Clavien PA. Liver ischemia: apoptosis as a central mechanism of injury. J Invest Surg. 2003;16:149-159

51. Natori S, Selzner M,Valentino KL, et al. Apoptosis of sinusoidal endothelial cells occurs during liver preservation injury by a caspase dependent mechanism. Transplantation. 1999;68:89-96

52. Savill JS, Wyllie AH, Henson JE, Walport MJ,et al. Macrophage phagocytosis of aging neutrophils in inflammation. Programmed cell death in the neutrophil leads to its recognition by macrophages. J Clin Invest. 1989;83:865-75

53. Alvarado-Kristensson M, Melander F, Leandersson $\mathrm{K}$ et al. p38- MAPK signals survival by phosphorylation of caspase- 8 and caspase -3 in human neutrophils. J Exp Med. 2004;199:449-58

54. Baskin-Bey ES, Canbay A, Bronk SF et al. Cathepsin B inactivation attenuates hepatocyte apoptosis and liver damage in steatotic livers after cold ischemia-warm reperfusion injury. Am J Physiol Gastrointest Liver Physiol. 2005;288:G396- G402

55. Kohli V, Gao W, Camargo CA, Clavien PA. Calpain is a mediator of preservationreperfusion injury in rat liver transplantation. Proc Natl Acad Sci USA. 1997;94:9354-9

56. Strasberg SM. Preservation injury and donor selection: it all starts here. Liver Transplant Surg. 1997;3:S1-S7

57. Bilzer M, Gerbes AL. Preservation injury of the liver: mechanisms and novel therapeutic strategies. J Hepatol. 2000;32:508-15 